\title{
Branding and Consumers' Narratives of Banking in the Financial Crisis
}

\author{
David A. Gilliam and Teresa K. Preston
}

\begin{abstract}
The financial crisis that began in 2008 offers an opportunity to examine consumer behavior in response to an industry crisis. Focus groups were used to gather consumer narratives of retail banking in the financial crisis. The personal narratives are useful in themselves as managerial touchstones and were further used to create possible archetypal narratives of groups of consumers and a cultural narrative or "big picture" view of the crisis. The narratives are examined through frameworks of both the humanities and psychology (narrative identity). The narrative results revealed the impact of the crisis on consumer's identity, views of other entities, and retail banking activity to yield actionable information for branding and communication. Narratives are shown to be a useful tool in examining consumers' reactions to an industry crisis and in formulating branding and communication responses.
\end{abstract}

\section{References available upon request.}

